\title{
Pivotal Roles of T-Helper 17-Related Cytokines, IL-17, IL-22, and IL-23, in Inflammatory Diseases
}

\author{
Ning Qu, ${ }^{1}$ Mingli Xu, ${ }^{2}$ Izuru Mizoguchi, ${ }^{3}$ Jun-ichi Furusawa, ${ }^{3}$ \\ Kotaro Kaneko, ${ }^{3}$ Kazunori Watanabe, ${ }^{3}$ Junichiro Mizuguchi, ${ }^{4}$ Masahiro Itoh, ${ }^{1}$ \\ Yutaka Kawakami, ${ }^{2}$ and Takayuki Yoshimoto ${ }^{3}$ \\ ${ }^{1}$ Department of Anatomy, Tokyo Medical University, 6-1-1 Shinjuku, Shinjuku-ku, Tokyo 160-8402, Japan \\ ${ }^{2}$ Division of Cellular Signaling, Institute for Advanced Medical Research School of Medicine, Keio University School of Medicine, \\ 35 Shinanomachi, Shinjuku-ku, Tokyo 160-8582, Japan \\ ${ }^{3}$ Department of Immunoregulation, Institute of Medical Science, Tokyo Medical University, 6-1-1 Shinjuku, Shinjuku-ku, \\ Tokyo160-8402, Japan \\ ${ }^{4}$ Department of Immunology, Tokyo Medical University, 6-1-1 Shinjuku, Shinjuku-ku, Tokyo 160-8402, Japan
}

Correspondence should be addressed to Takayuki Yoshimoto; yoshimot@tokyo-med.ac.jp

Received 12 April 2013; Accepted 25 June 2013

Academic Editor: William O’Connor Jr.

Copyright (C) 2013 Ning Qu et al. This is an open access article distributed under the Creative Commons Attribution License, which permits unrestricted use, distribution, and reproduction in any medium, provided the original work is properly cited.

T-helper 17 (Th17) cells are characterized by producing interleukin-17 (IL-17, also called IL-17A), IL-17F, IL-21, and IL-22 and potentially TNF- $\alpha$ and IL-6 upon certain stimulation. IL-23, which promotes Th17 cell development, as well as IL-17 and IL-22 produced by the Th17 cells plays essential roles in various inflammatory diseases, such as experimental autoimmune encephalomyelitis, rheumatoid arthritis, colitis, and Concanavalin A-induced hepatitis. In this review, we summarize the characteristics of the functional role of Th17 cells, with particular focus on the Th17 cell-related cytokines such as IL-17, IL-22, and IL-23, in mouse models and human inflammatory diseases.

\section{Introduction}

$\mathrm{CD}^{+}$T-helper (Th) cells play a central role in initiating and maintaining diverse immune responses. Functionally distinct Th cells are induced when naive $\mathrm{T}$ cells are stimulated via $\mathrm{T}$ cell receptor engagement in conjunction with costimulatory molecules and cytokines produced by innate immune cells. Classically, Th1 cells regulate cellular immunity via production of interferon (IFN)- $\gamma$, whereas Th 2 cells regulate humoral immunity via production of interleukin (IL)-4, IL5 , and IL-13 $[1,2]$. Regulatory T cells (Tregs), a third subset of $\mathrm{CD} 4^{+} \mathrm{T}$ cells, regulate the activation and expansion of these lineages via expression of forkhead box P3 and/or their capacity to produce cytokines such as transforming growth factor (TGF)- $\beta$, IL-10, and IL-35 $[3,4]$. Recently, the identification of a novel lineage of helper T cells, Th17, has broken the long-held paradigm regarding the roles of the other three lineages (Th1, Th2, and Treg) (Figure 1). Distinguished by the production of IL-17 (also called IL-17A), these Th17 cells are developed from naive $\mathrm{CD} 4^{+} \mathrm{T}$ cells under the influence of a network of inflammatory cytokines, including IL-1, IL-6, and TGF- $\beta$, which support the commitment to this lineage. Although IL-23 was previously reported to be necessary for Th17 differentiation, it is currently thought that IL-23 plays an important role in the survival and expansion of pathological Th17 cells [5-9].

Th17 cells were first defined by their expression of IL-17A, but they have since been shown also to preferentially express IL-22, as well as IL-17F, IL-21, GM-CSF, and potentially TNF$\alpha$ and IL-6 [10, 11]. However, it is becoming apparent that the IL-22 expression profile differs from that of IL-17A. Whereas TGF- $\beta$ and IL- 6 are both necessary for induction of IL-17A, IL- 22 can be induced via IL- 6 alone, and increasing amounts of TGF- $\beta$ are actually inhibitory to the expression of IL-22 [12]. Accumulating data suggest that Th17 cells play a significant role in infectious diseases, autoimmune conditions, 


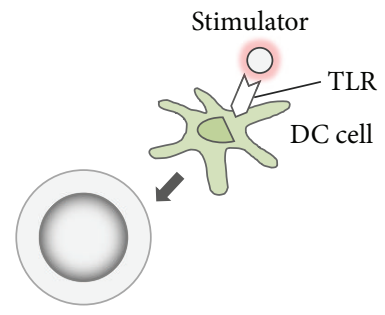

Naive $\mathrm{CD} 4^{+} \mathrm{T}$ cell

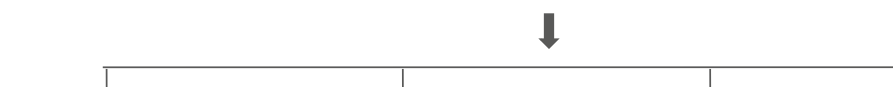

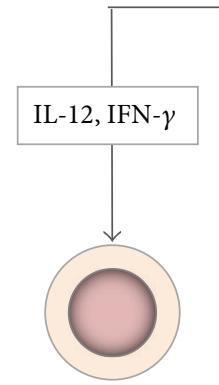

Th1 cell

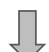

IFN- $\gamma$, TNF- $\alpha$
Cellular immune response

Organ-specific autoimmunity, intracellular infections

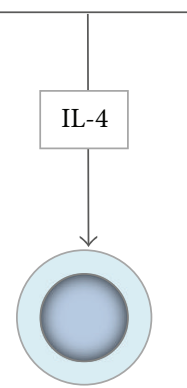

Th2 cell

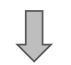

IL-4, IL-5, IL-13

Humoral immune response Extracellular parasites, allergic diseases, asthma, atopic disorders

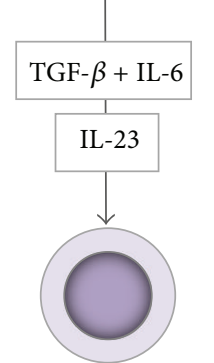

Th17 cell
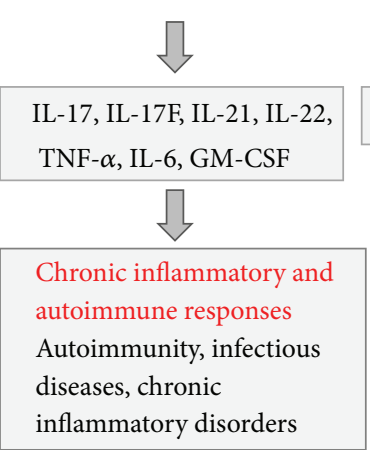

inflammatory disorders

Figure 1: Differentiation of naïve $\mathrm{CD}^{+} \mathrm{T}$ cells. Upon certain stimulating conditions, naïve $\mathrm{CD} 4^{+} \mathrm{T}$ cells differentiate into different subpopulations, such as Th1, Th2, Th17, and regulatory T cells (Tregs). Th1: T-helper 1 cell; Th2: T-helper 2 cell; Th17: T-helper 17 cell; IL: interleukin; TGF- $\beta$ : transforming growth factor- $\beta$; IFN- $\gamma$ : interferon- $\gamma$; TNF- $\alpha$ : tumor necrosis factor- $\alpha$; GM-CSF: granulocyte macrophage colony-stimulating factor; DC: dendritic cell; RA: retinoic acid.

adoptive immune response, and mucosal immunity [13-16]. The polarization of Th17 cells relies critically upon the actions of cytokines (e.g., IL-23) secreted by antigen-presenting cells (APCs) $[14,17,18]$. In addition to the inflammatory diseases, IL-23 also plays essential roles during tumorigenesis [19].

Based on evidence that Th17 cells can mediate inflammation and tissue destruction [20,21], there has been intense interest in defining their origins and functions and developing strategies to block their pathological effects. In this review, we highlight studies that provide significant evidence for a role of Th17 cells in human diseases and animal models, and we briefly review the role of Th17 cells by focusing on the production of cytokines in inflammatory diseases (Figure 2).

\section{Th17 Cells in Inflammatory Skin Diseases}

Inflammatory skin diseases include psoriasis, allergic contact dermatitis, and atopic dermatitis. Psoriasis is a complex autoimmune skin disease characterized by interactions between dendritic cells (DCs), T cells, and keratinocytes [22, 23]. Although mice with epidermal acanthosis and dermal inflammation induced by IL-23 injection into the ear are not an exact model for psoriasis, many of the features in this model, such as IL-22 upregulation and STAT3 activation, are similar to the features evident in psoriasis.

In psoriasis, IL-23 is produced at high levels by DCs and keratinocytes, and this cytokine stimulates Th17 cells to produce IL-17A and IL-22. Several groups reported that psoriatic lesions showed increased mRNA levels of the IL23/Th17 axis, including IL-23p19, IL-12/23p40, IL-22, IL-17A, and IL-17F, whereas mRNA levels of IL-12p35 and IL-4 were not elevated [24-26]. Furthermore, evidence for the role of IL-23 in the pathogenesis of psoriasis was substantiated by the initiation of the psoriasis-like disease acanthosis following repeated injections of IL-23 in mice [12]. More recent studies have also revealed that polymorphisms in the IL-12/23p40 and IL-23 receptor (IL-23R) are associated with psoriasis [27]. Ustekinumab, an anti-IL-12/23p40 antibody, has been used to 


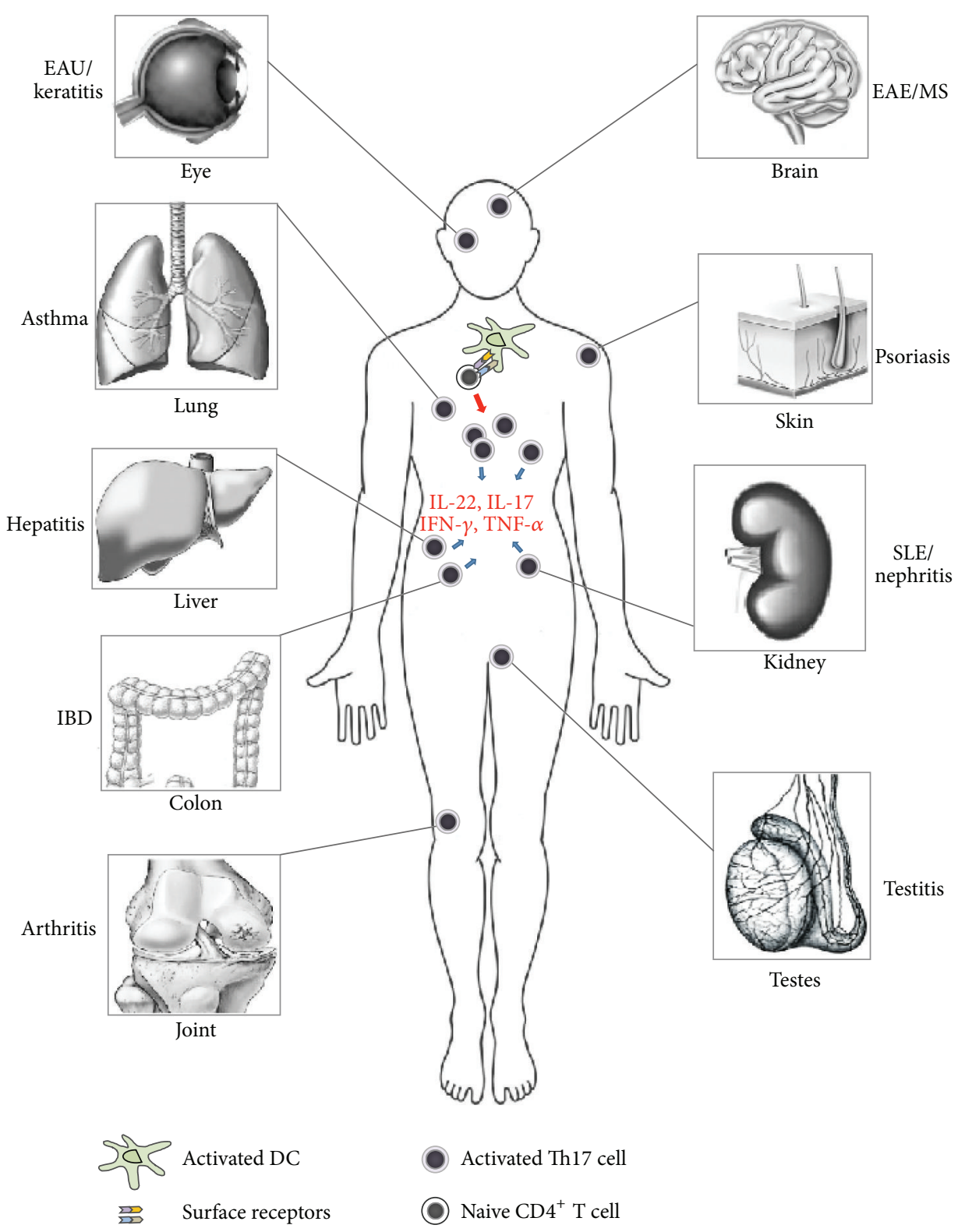

FIGURE 2: Schematic representation of Th17 cell-induced inflammatory diseases in humans. Inflammation mediated by Th17 cells has been identified in several human organs or tissues, including the eye, brain, skin, liver, colon, kidney, testes, joint, and lung. Numerous cytokines induced by activated Th17 cells, such as IL-22, IL-17, IFN- $\gamma$, TNF- $\alpha$, and IL- 6 , play essential roles during the inflammatory diseases. These cytokines lead to the onset of the uveitis, autoimmune encephalomyelitis, psoriasis, hepatitis, inflammatory bowel disease, nephritis, testitis, rheumatic arthritis, and asthma. The counteraction between protective cytokines and pro-inflammatory cytokines decides the final outcome in the organ or tissue.

treat plaque psoriasis [28]. In transgenic mice, overexpression of individual subunits of IL-23 led to inflammation [29]. In another mouse study, recombinant IL-23 injected into normal skin produced erythematous skin with histologic characteristics of psoriasis [30].

IL-22 is a key cytokine produced by Th17 cells, and it plays an important role in maintaining homeostasis and remodeling epithelial tissues. The importance of IL-22 has been highlighted in the pathogenesis of psoriasis [12]. IL22 mRNA expression is upregulated in psoriatic skin as compared to normal skin, whereas the levels of IL-22 mRNA in peripheral blood mononuclear cells from psoriatic patients and normal controls were similar [31]. Using IL-22-deficient mice, Zheng et al. showed that in the absence of IL-22, IL23-mediated dermal inflammation was reduced [12]. Another study also showed that IL-22 is required for psoriasis-like lesions in the mouse Imiquimod model. Imiquimod-induced scaly skin lesions were almost totally absent in IL-22-deficient mice or in mice treated with anti-IL-22 antibody. Importantly, IL-22 mediates keratinocyte activation via phosphorylation of STAT3, leading to acanthosis that is associated with a psoriatic phenotype $[12,32]$.

In addition, injection of IL-23 enhances IL-17A expression in mouse skin, but pretreatment of anti-IL-17A antibody 
does not ameliorate the formation of psoriatic lesions [30]. This observation suggests that IL-17A is dispensable during IL-23-dependent psoriasis. Skin biopsy samples from patients with psoriasis showed elevated expression levels of IL-17 together with high expression of IL-23 and IL-22 [12, 33]. Although there was no difference between the levels of IL-17 in the sera of patients with psoriasis and in controls, there was a correlation between serum levels of IL-17 and the severity of psoriasis [34].

\section{Th17 Cells in Inflammatory Bowel Diseases}

Inflammatory bowel disease (IBD), including Crohn's disease and ulcerative colitis, is a chronic inflammatory disease of the gastrointestinal tract. IBD is caused by aberrant innate and/or adaptive immune responses [35]. IBD had long been described as a Thl-mediated disease because IFN- $\gamma$ is essential for disease progression [36]. However, the recent discovery of Th17 cells has revealed a key role of this subset of $\mathrm{T}$ cells in IBD.

IL-23 is essential for the development of IBD in mouse models $[37,38]$, and protective IL-23R polymorphisms in the human population were identified through a genome association study [39]. However, IL-22 stimulates epithelial cell growth, goblet cell hyperplasia, and antimicrobial production. IL-22-mediated protective effects were seen in the T cell transfer colitis model [40]. IL-22 is highly upregulated in the sera and lesions of patients with either Crohn's disease or ulcerative colitis [41]. Moreover, activation of aryl hydrocarbon receptor (AHR) results in the elevated production of IL-22 in particular and reduction of Th1 and Th2 cytokines $[42,43]$. Blockade of IL-22 by using its neutralizing antibody reversed the therapeutic effect of 6 -formylindolo $(3,2-b)$ carbazole on the trinitrobenzenesulfonic acid-induced colitis in mice. Thus, induction of IL-22 is one of the major mechanisms controlling pathogenesis in the gut through the AHR signaling pathway [44].

On the other hand, IL-17 is produced in healthy gut. A recent study suggested that IL-17F, but not IL-17A, was required to induce severe immunopathology in the dextran sulfate sodium-induced colitis model [45]. In contrast, antiIL-17A monoclonal antibody treatment was demonstrated to aggravate dextran sulfate sodium-induced colitis, and blockade of IL-17A in colitis of IL-10 knockout mice was inefficient in reducing disease unless IL-6 was also neutralized [46, 47]. Another study demonstrated that adoptive transfer of IL-17Adeficient naïve $\mathrm{CD} 4^{+} \mathrm{T}$ cells or transfer of IL-17 receptordeficient $\mathrm{T}$ cells to recipient immunedeficient mice induces severe colitis [48], suggesting that IL-17 exerts a protective effect on T cells. Collectively, these results indicate that Th17 cytokines have both anti- and pro-inflammatory effects in the gut, depending on the microenvironments.

\section{Th17 Cells in Experimental Autoimmune Encephalomyelitis/Multiple Sclerosis}

Experimental autoimmune encephalomyelitis (EAE), which resembles an autoimmune inflammatory disease of human multiple sclerosis (MS), was classically believed to be mediated by Thl cells and inflammatory macrophages. However, the concept that Th1 response is centrally important for autoimmunity was challenged by evidence that animals lacking a functional Th1 response still develop aggravated autoimmune encephalomyelitis. Recent studies demonstrated an association between the development of demyelinating plaques and the accumulation of Th17 cells in EAE and MS.

IL-23 plays a pivotal role in the development of EAE. Mice deficient in IL-23p19 or IL-23R knockout mice were resistant to $\operatorname{EAE}[5,49,50]$. Moreover, IL-23R is expressed in macrophages infiltrating the central nervous system, and macrophages expressing IL-23R in response to IL-23 produce IL-22 and IL-17 [5, 50].

In addition, IL-17 (IL-17A) also plays a pro-inflammatory role during the development of EAE, as shown by several lines of evidence. First, IL-17F knockout mice with normal levels of IL-17A showed only marginally reduced EAE [45]. Second, IL-17A knockout mice with normal levels of IL-17F showed milder disease [51]. Finally, IL-17A knockout mice with reduced levels of IL-17F exhibited clearly reduced EAE [15]. Moreover, administration of anti-IL-17A antibody could attenuate EAE but not completely prevent this disease [52].

Although IL-22 can be induced from Th17 cells by IL-23 during inflammation, IL-22 seems to have no effect on the development of EAE. Kreymborg et al. showed that IL-22 knockout mice are not protected from EAE [53].

In MS patients, IL-17 mRNA and protein levels were increased in both brain lesions and mononuclear cells isolated from blood and cerebrospinal fluids [54, 55]. Although these observations suggest that IL-17 may contribute to the development of MS in humans, further research is needed to elucidate the precise role of this cytokine in the pathogenesis of MS. In addition, because IL-23 plays a pivotal role in EAE, administration of monoclonal antibody specific for IL-23p19 instead of IL-17A or IL-17F might prevent this disease [56]. Based on these results, neutralization of IL-23 may be an effective therapeutic approach to treat EAE/MS.

\section{Th17 Cells in Rheumatoid Arthritis}

Rheumatoid arthritis (RA) is a chronic inflammatory disease associated with the destruction of affected joints, and it represents one of the most common autoimmune-related diseases. Although RA had long been classified as a Th1mediated disease, it is now thought to be a primarily Th17driven disease [57].

Initial evidence for a pathogenic role of IL-17 in RA came from reports that IL-17 was increased in the sera and synovial fluids of RA patients [58-60]. Long-term intraarticular administration of IL-17 via gene transfer reproduced the key features of RA, including massive inflammation, bone erosions, and cartilage damage [61]. As with psoriasis, there is also increased IL-22 and IL-23 in the synovium of RA patients $[62,63]$. Notably, the increase in IL-17 and IL-23 appears to be specific for RA, but not for osteoarthritis $[64,65]$. Conversely, inhibition of IL17 by antibodies against IL-17A or its receptor IL17RA protected against the development of arthritis [66]. 
Because cyclosporine A can inhibit the production of IL-17 by memory Th17 cells in healthy donors and RA patients [67], this could be an effective strategy to limit the disease. Furthermore, mice lacking IL-17RA develop a very mild form of experimental arthritis [68]. TNF has been shown to be a key cytokine in the collagen-induced arthritis model. Although TNF contributes to the pathogenesis of the early stages of the disease, it is not involved in the later stages. In contrast, IL-17 has a role throughout all stages of chronic disease [69]. This finding is another indication that IL-17 contributes to the chronicity of RA. Therapeutic strategies that specifically block Thl7 cell development are expected to be highly effective in treating RA patients.

\section{Th17 Cells in Renal Inflammation}

Several recent studies have emphasized the functional importance of Th17-induced immune response in renal inflammatory diseases. We discuss the potential roles of the Th17 immune response in experimental murine models and humans.

6.1. Th17 Cells in Experimental Animal Models with Nephritis. The first evidence for the importance of TH17 cells in renal inflammation was provided by a murine model of crescentic glomerulonephritis [70, 71]. Recently, Th17 cells were identified in murine kidneys after ureteral obstruction [72]. In addition, the IL-23/IL-17 pathway was demonstrated to contribute significantly to renal tissue injury in experimental glomerulonephritis by analysis of nephrotoxic nephritis in both IL-23p19 and IL-17 knockout mice [70]. Moreover, IFN- $\gamma$ plays a protective role in experimental autoimmune anti-glomerular basement membrane (anti-GBM) glomerulonephritis, as revealed by the fact that IFN- $\gamma$-deficient mice develop more severe anti-GBM disease [73]. In contrast, IL-23p19 and IL-17A knockout mice are protected from anti-GBM disease after treatment with anti-mouse GBM antibodies [70]. In addition, by using IL-12p35, IL-12p40, and IL-23p19 knockout mice, Ooi et al. demonstrated that mice deficient in IL-23, but not IL-12, were protected from glomerulonephritis [74]. Neutrophils were recently identified to be an early source of IL-17 in renal inflammation in a mouse kidney ischemia reperfusion injury model [75].

6.2. Th17 Cells in Human Renal Inflammation. There is only limited evidence of the involvement of Th17 cells/IL-17 in the pathogenesis of renal autoimmunity in humans. The contribution of IL-17 to inflammatory reactions in the kidney was initially reported in an in vitro study of patients suffering from renal transplantation graft rejection [76]. Recently, upregulation of IL-17 mRNA expression in the urinary sediment of patients with systemic lupus erythematosus (SLE) and increased percentage of Th17 cells in patients with active SLE were reported $[77,78]$. Although serum IL-17 levels were significantly increased in SLE patients compared with normal controls, associations between serum IL-17 levels and clinical parameters were demonstrated [79]. Another study reported that a lower percentage of Th2 2 cells and higher percentage of Th17 cells are present in patients with lupus nephritis compared with healthy controls [80]. Th22 cells are a new subset of $\mathrm{CD}^{+}{ }^{+} \mathrm{T}$ helper differentiated from naïve $\mathrm{T}$ cells and characterized by secretion of IL-22 but not IL-17 or IFN- $\gamma$ $[43,81]$. IL-22 may play a protective role in preventing the development of lupus nephritis, although future research is necessary to identify the real role of IL-22 in SLE.

\section{Th17 Cells in Hepatitis}

7.1. Th17 Cells in Experimental Hepatitis Models. Intravenous administration of Concanavalin A (Con A) results in rapid liver inflammation and necrosis [82]. Many features of Con A-induced liver injury are believed to mimic human autoimmune and viral liver disorders. Numerous experiments have also shown that IL-22 plays a protective role in mice with hepatitis $[83,84]$. However, there are conflicting reports regarding the susceptibility of $I L-17$-deficient mice to Con A-induced acute hepatitis $[84,85]$. IL-17 is critical in the induction of liver injury and is induced during Con A hepatitis [86, 87]. Moreover, both IL-17A and IL-17F function via the IL-17 receptor (IL-17R), and both $I L-17 A$ and $I L$ $17 \mathrm{~F}$ are overexpressed in IL-17R-deficient mice, suggesting that a feedback loop acts on Th17 cells $[88,89]$. In addition, IL-17 activates other cell types in the liver to produce proinflammatory cytokines beneficial to hepatocyte apoptosis [90].

Notch is an evolutionarily conserved molecule that controls the cell fate decision in a variety of cells $[91,92]$. We previously demonstrated that Notch signaling drives IL-22 secretion by stimulating the AHR [93]. Mice that are deficient in RBP-J, a key mediator of Notch signaling, are highly susceptible to the detrimental immunopathology associated with Con A-induced hepatitis with little IL-22 production [93] (Figure 3). Although IL-6 has the ability to induce IL22 production [12], and IL-6-deficient mice were shown to be highly susceptible to liver damage [94], these mice were reported to have no impairment in IL-22 expression during Con A-induced hepatitis [84]. IL-23 also has the ability to induce the production of IL-22 [12] and IL-17 [95]. However, there are conflicting reports regarding the role of IL-17 in Con A-induced hepatitis and the susceptibility of IL-17-deficient mice to hepatitis $[84,85]$. Therefore, the role of IL-23 in the induction of IL-22 and IL-17 production and liver damage during Con A-induced hepatitis using IL23p19- and IL-17-deficient mice was investigated [86]. These results revealed that the endogenous IL-23 plays a protective role in hepatitis in an IL-22-dependent manner, whereas exogenous IL-23 plays a pathological role in IL-17-dependent and -independent manners. Further studies are necessary to elucidate the precise role of exogenous IL-23 in Con Ainduced hepatitis.

7.2. Th17 Cells in Human Liver Diseases. Chronic hepatitis $B$ virus (HBV) or hepatitis $C$ virus infection leads to liver disease. Such infective disease is associated with $\mathrm{T}$ cell activation and the secretion of numerous pro-inflammatory cytokines, such as IFN- $\gamma$. Nonetheless, although IL-22 shows 


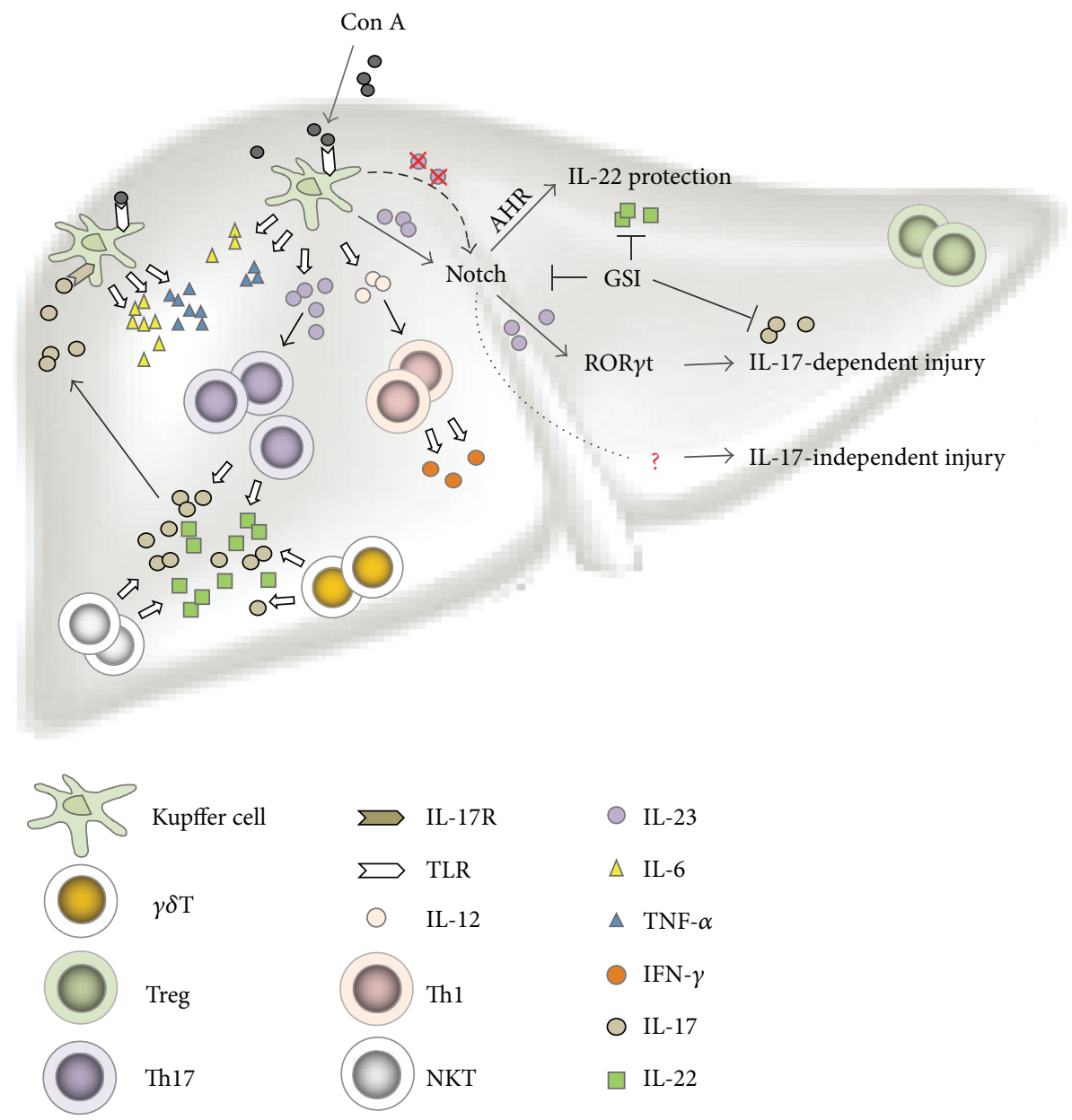

Figure 3: Schematic diagram of the role of activated Th17 cells during Con A-induced hepatitis. Con A injection induces IL-23 expression from Kupffer cells (also inducing IL-12, IL-6, TNF- $\alpha$, and other cytokines) in the liver, then activates Notch signaling in activated Th17 cells (and other types of T cells). AHR-dependent production of IL-22 is pivotal for protection, and ROR $\gamma \mathrm{t}$-dependent production of IL-17 is critical for pathogenesis. The IL-17/IL-17R signaling pathway also exacerbates hepatitis by inducing TNF- $\alpha$ and IL-6. Con A: Concanavalin A; AHR: aryl hydrocarbon receptor; ROR $\gamma$ t: retinoic acid-related orphan receptor $\gamma \mathrm{t}$; TLR: toll-like receptor; GSI: $\gamma$-secretase inhibitor; IL-17R: interleukin-17 receptor.

a marked protective role in Con A-induced hepatitis, IL22 also enhances the pro-inflammatory activity of TNF- $\alpha$ expressed in the liver after transfer of HBV-specific T cells [96]. Another study reported that IL-22 neutralization ameliorates liver damage after transferring $\mathrm{HBV}$-specific $\mathrm{T}$ cells by using a transgenic mouse model of HBV replication [97]. During acute liver inflammation, IL-22 protects hepatocytes from injury, possibly through STAT3-mediated upregulation of prosurvival and proliferative responses. During chronic inflammation, IL-22 may also help to limit damage and allow survival of damaged hepatocytes that are precursors for hepatocellular carcinomas [98]. Future research is necessary to examine the role of IL-22 in chronic inflammation and the development of liver cancer. In patients with chronic HBV infection, Th17 cells are highly increased in both peripheral blood and liver, and they exhibit a potential to aggravate liver damage during chronic HBV infection [99]. Thus, Th17 cells may be involved in both the pathogenesis and antiinflammatory responses in human liver diseases.

\section{Th17 Cells in Ophthalmic Inflammation}

8.1. Th17 Cells in Experimental Autoimmune Uveitis. The eye is an immune-privileged organ, and immune privilege is a complex phenomenon that involves multiple components. Uveitis is a sight-threatening intra-ocular inflammatory disease that is predominantly mediated by Th1 and Th17 [100]. Experimental autoimmune uveitis (EAU) is an animal model of human autoimmune uveitis, and activated Th1 and Th17 cells are considered to play a major role in initiating the intraocular inflammation [101].

The initial evidence indicated that Th1 cells predominantly produce IFN- $\gamma$ in experimental and clinical uveitis [102-104]. However, it is now clear that IL-17-producing Th17 cells, but not IFN- $\gamma$-producing Th1 cells, are the true mediators of tissue-specific ocular pathogenesis [81, 105]. Neutralization of IL-17, but not IFN- $\gamma$, in mice prevents and ameliorates EAU $[104,106]$. Several recent studies suggested that IL-17 has both pro- and anti-inflammatory effects on the 
development of EAU [107, 108]. Furthermore, a protective role of IL-22 by inducing regulatory $\mathrm{CD}_{11 b^{+}}$APCs has been described in EAU [109]. In addition, $\mathrm{CD} 4^{+} \mathrm{T}$ cells are necessary for initiating EAU, and depletion of $\mathrm{CD}_{4}^{+}$ $\mathrm{T}$ cells prevents EAU development. Furthermore, antigenspecific $\mathrm{CD} 8^{+} \mathrm{T}$ cells also act as regulatory cells to suppress EAU $[110,111]$. Similar to other autoimmune animal models, costimulatory signals such as CD40, CD80, and CD86 are also involved in the course of EAU, and blockade of these signals ameliorates intra-ocular inflammation [112-116].

8.2. Th17 Cells in Keratitis. IL-17A-producing cells are present in the midperipheral cornea in a mouse model of dry eye disease, as well as in corneas from patients with herpetic stromal keratitis (SK) [117-119]. The cornea infection with herpes simplex virus (HSV) 1 leads to SK, a blinding immuneinflammatory lesion of the eye. IL-17 is upregulated after HSV infection of the cornea [120]. HSV infection of IL-17R knockout mouse as well as IL-17 neutralization in wild-type mouse showed reduced SK damage [120]. In addition, administration of 2,3,7,8-tetrachlorodibenzo-p-dioxin, which is a ligand for AHR, caused a significant induction of Tregs and inhibited the differentiation of Th1 and Th17 cells, resulting in suppression of the severity of SK damage [121].

Staphylococcus aureus and Pseudomonas aeruginosa often cause bacterial keratitis, and these bacteria predominantly invade corneal epithelial cells [122]. IL-6, one of the major cytokines responsible for differentiating into Th17 cells, is expressed in the corneal epithelial and conjunctival cell lines [123]. Desiccating stress in the murine dry eye model, similar to human dry eye, also causes ocular surface inflammation characterized by increasing IL-6 and IL-17A expression [118]. In general, IL-17RA is constitutively expressed in cornea and conjunctiva. When infected with $S$. aureus, human corneal epithelial cells were demonstrated to increase the production of IL-6 but show no change of IL-17A and IL-17RA in vitro [124].

\section{Th17 Cells in Testes}

The testis is an immunologically privileged site where germ cell antigens are protected from autoimmune attack [125128]. Multiple mechanisms prevent autoimmune disease in the testes, including the structure of the blood-testis barrier and secretion of immunosuppressive factors mainly by macrophages, Sertoli, peritubular, and Leydig cells. Studies established the presence of several $\mathrm{T}$ cell subsets $\left(\mathrm{CD}^{+}\right.$ and $\mathrm{CD}^{+} \alpha \beta$ T cells, $\gamma \delta \mathrm{T}$ cells, and NK cells) and Tregs, as modulators of immune response acting through local and systemic mechanisms, in normal testicular interstitium of human and rodents $[129,130]$. However, the testicular environment does not preclude inflammatory reactions and recruitment of tissue-specific $T$ lymphocytes, which appear to be crucial components of the inflammation cascade $[131,132]$. In fact, testicular inflammatory disorders leading to impairment of spermatogenesis are thought to be a primary reason for male infertility [133-135]. The recruitment of immune cells in testicular interstitium (mainly DCs, macrophages, and T cells) and secretion of pro-inflammatory cytokines (IL6 , IFN- $\gamma$, TNF- $\alpha$, IL-12, IL-17, and IL-23), which disrupt the normal testicular immunosuppressive microenvironment, occur during inflammation induced by infectious agents or develop in different pathologies, such as experimental autoimmunity orchitis (EAO) [136]. In the rat testis of EAO, it was demonstrated that not only $\mathrm{CD}^{+}$cells (Th17) but also $\mathrm{CD}^{+}{ }^{+} \mathrm{T}$ cells produce IL-17 (Tc17). Both $\mathrm{CD} 4^{+}$and $\mathrm{CD}^{+} \mathrm{T}$ cells are the major contributors during the onset and chronic phases of EAO [136]. In human azoospermic testis with chronic inflammation, Th17 cells, which are orchestrated by IL-23 produced from APCs, are critically involved in chronic inflammation [137]. Such patients have increased levels of Th17 cells, their cytokines such as IL-17A, IL-21, and IL-22, and IL-23-producing CD11c ${ }^{+}$DCs and CD68 ${ }^{+}$ macrophages [137]. Moreover, because IL-17 was expressed not only in normal testis but also in higher levels in azoospermic testis, IL-17 might be involved in the maintenance of testicular immune privilege and spermatogenesis $[137,138]$. In addition, pro-inflammatory cytokines including IL-1 and IL-6 have direct effects on spermatogenic cell differentiation and testicular steroidogenensis within the normal testis [139]. However, increased numbers and expression level of IL17A-immunoreactive cells in azoospermic testis with chronic inflammation indicate that overexpression of IL-17A can substantially damage the blood-testis barrier and probably destroy normal spermatogenesis and germ cells, which in turn could ultimately lead to azoospermia.

IL-17-deficient mice showed decreased antigen-specific $\mathrm{T}$ cell activation and antibody production in models of autoimmune and allergic diseases [140]. In addition to the signature cytokine IL-17A (IL-17), Th17 cells also produce IL-17F, IL-21, and IL-22, which would also allow Th17 cells to communicate with a wide variety of immune and nonimmune cells [14]. A recent study demonstrated that the small molecule halofuginone can selectively inhibit mouse and human Th17 cell differentiation and autoimmune inflammation in vivo through a cytoprotective signaling pathway [141]. An understanding of the development, function, and regulation of Th17 cells in testicular immunopathology is critical for designing better strategies for the treatment of immunological male infertility.

\section{Th17 Cells in Allergic Airway Disease}

Asthma is characterized by an inflammatory reaction associated with increased production of Th2 type cytokines, such as IL-4 and IL-13.

10.1. Th17 Cells in Mouse Models. Numerous studies have shown that Th17 cytokines play an essential role in allergic airway disease, and the role of Th17 cells was investigated in several mouse models. A study of IL-17RA knockout mice demonstrated decreased ovalbumin-induced airway eosinophilia and Th2-related cytokines [142]. IL-17A knockout mice showed attenuated airway eosinophilia and neutrophilia, whereas IL-17F knockout mice demonstrated elevated eosinophil recruitment. These findings suggest that 
IL-17 drives the allergic Th2 response. Other studies also confirmed that IL-17 promotes ovalbumin-induced Th2 responses by synergizing with IL-4 and IL-13 [143]. Unlike IL-17, which has a pro-inflammatory role during allergic airway disease, IL-22 seems to suppress Th2-mediated inflammation. Treatment with anti-IL-22 antibody exacerbated airway eosinophilia, suggesting that IL-22 may have antiinflammatory properties in airway disease [144]. In contrast, IL-23 knockout mice showed ameliorated eosinophilia compared to IL-23 overexpression mice $[145,146]$.

10.2. Th17 Cells in Human Asthma. The role of Th17 cells in human asthma remains largely elusive. In humans, increased expression of IL-17A and IL-17F was detected in bronchial submucosa, and examination of sputum in patients with asthma demonstrated that neutrophils were present, particularly in severe forms of this disease [147]. Furthermore, Lajoie et al. demonstrated a direct link among C5aR signaling, IL-17A production, and severe airway hyperresponsiveness; the sensitivity of airway hyperresponsiveness noted in mice after C5aR blockade is completely reversed by concurrent IL17A blockade [148]. In addition, polymorphisms in the $I L$ $17 \mathrm{~A}$ gene related to asthma risk have been reported [149]. Further studies are necessary to clarify whether IL-17 is a safe therapeutic target for asthma therapy.

\section{Conclusion}

Th17 cells, which are directly involved in and mediate chronic inflammation, are characterized by the production of cytokines such as IL-17 and IL-22 as well as the recruitment of neutrophils and other inflammatory cells. Under certain circumstances, the same cytokine plays opposite roles in different tissues. For instance, IL-22 plays a protective role in Con A-induced acute hepatitis but a pro-inflammatory role in psoriasis. In different tissues, the counteraction between protective cytokines and pro-inflammatory cytokines should determine the final outcome of the immune responses. Although some conflicting findings still need to be resolved, targeting Th17 cells and their related cytokines such as IL-17, IL-22, and IL-23 may be an effective therapeutic approach for chronic inflammation in the future.

\section{Authors' Contribution}

N. Qu and M. Xu contributed equally to this work.

\section{Acknowledgment}

This work was partly supported by Grants-in-Aid for Scientific Research from the Japan Society for the Promotion of Science (number 23590475). The authors have no conflict of interests.

\section{References}

[1] A. K. Abbas, K. M. Murphy, and A. Sher, "Functional diversity of helper T lymphocytes," Nature, vol. 383, no. 6603, pp. 787-793, 1996.
[2] L. H. Glimcher and K. M. Murphy, "Lineage commitment in the immune system: the T helper lymphocyte grows up," Genes and Development, vol. 14, no. 14, pp. 1693-1711, 2000.

[3] D. A. A. Vignali, L. W. Collison, and C. J. Workman, "How regulatory T cells work," Nature Reviews Immunology, vol. 8, no. 7, pp. 523-532, 2008.

[4] S. E. Allan, R. Broady, S. Gregori et al., "CD4 ${ }^{+}$T-regulatory cells: toward therapy for human diseases," Immunological Reviews, vol. 223, no. 1, pp. 391-421, 2008.

[5] D. J. Cua, J. Sherlock, Y. Chen et al., "Interleukin-23 rather than interleukin-12 is the critical cytokine for autoimmune inflammation of the brain," Nature, vol. 421, no. 6924, pp. 744$748,2003$.

[6] L. E. Harrington, R. D. Hatton, P. R. Mangan et al., "Interleukin 17-producing $\mathrm{CD} 4^{+}$effector T cells develop via a lineage distinct from the T helper type 1 and 2 lineages," Nature Immunology, vol. 6, no. 11, pp. 1123-1132, 2005.

[7] C. L. Langrish, Y. Chen, W. M. Blumenschein et al., "IL-23 drives a pathogenic $T$ cell population that induces autoimmune inflammation," Journal of Experimental Medicine, vol. 201, no. 2, pp. 233-240, 2005.

[8] H. Park, Z. Li, X. O. Yang et al., "A distinct lineage of CD4 T cells regulates tissue inflammation by producing interleukin 17," Nature Immunology, vol. 6, no. 11, pp. 1133-1141, 2005.

[9] M. Veldhoen, R. J. Hocking, R. A. Flavell, and B. Stockinger, "Signals mediated by transforming growth factor- $\beta$ initiate autoimmune encephalomyelitis, but chronic inflammation is needed to sustain disease," Nature Immunology, vol. 7, no. 11, pp. 1151-1156, 2006.

[10] S. C. Liang, X. Tan, D. P. Luxenberg et al., "Interleukin (IL)22 and IL-17 are coexpressed by Th17 cells and cooperatively enhance expression of antimicrobial peptides," Journal of Experimental Medicine, vol. 203, no. 10, pp. 2271-2279, 2006.

[11] T. Korn, E. Bettelli, W. Gao et al., "IL-21 initiates an alternative pathway to induce proinflammatory T H17 cells," Nature, vol. 448, no. 7152, pp. 484-487, 2007.

[12] Y. Zheng, D. M. Danilenko, P. Valdez et al., "Interleukin-22, a TH17 cytokine, mediates IL-23-induced dermal inflammation and acanthosis," Nature, vol. 445, no. 7128, pp. 648-651, 2007.

[13] N. J. Wilson, K. Boniface, J. R. Chan et al., "Development, cytokine profile and function of human interleukin 17producing helper T cells," Nature Immunology, vol. 8, no. 9, pp. 950-957, 2007.

[14] C. Dong, "TH17 cells in development: an updated view of their molecular identity and genetic programming," Nature Reviews Immunology, vol. 8, no. 5, pp. 337-348, 2008.

[15] T. Korn, E. Bettelli, M. Oukka, and V. K. Kuchroo, "IL-17 and Th17 cells," Annual Review of Immunology, vol. 27, pp. 485-517, 2009.

[16] D. R. Littman and A. Y. Rudensky, "Th17 and regulatory T cells in mediating and restraining inflammation," Cell, vol. 140, no. 6, pp. 845-858, 2010.

[17] I. Gutcher and B. Becher, "APC-derived cytokines and T cell polarization in autoimmune inflammation," Journal of Clinical Investigation, vol. 117, no. 5, pp. 1119-1127, 2007.

[18] S. Saijo, S. Ikeda, K. Yamabe et al., "Dectin-2 recognition of $\alpha$ mannans and induction of Th17 cell differentiation is essential for host defense against candida albicans," Immunity, vol. 32, no. 5, pp. 681-691, 2010.

[19] T. Yoshimoto, M. Xu, I. Mizoguchi, N. Morishima, Y. Chiba, and J. Mizuguchi, "Regulation of antitumor immune responses 
by the IL-12 family cytokines, IL-12, IL-23, and IL-27,' Clinical and Developmental Immunology, vol. 2010, Article ID 832454, 9 pages, 2010.

[20] A. Fischer, "Human immunodeficiency: connecting STAT3, Th17 and human mucosal immunity," Immunology and Cell Biology, vol. 86, no. 7, pp. 549-551, 2008.

[21] L. A. Tesmer, S. K. Lundy, S. Sarkar, and D. A. Fox, “Th17 cells in human disease," Immunological Reviews, vol. 223, no. 1, pp. 87-113, 2008.

[22] F. O. Nestle, L. A. Turka, and B. J. Nickoloff, "Characterization of dermal dendritic cells in psoriasis. Autostimulation of $\mathrm{T}$ lymphocytes and induction of Th1 type cytokines," Journal of Clinical Investigation, vol. 94, no. 1, pp. 202-209, 1994.

[23] M. A. Lowes, F. Chamian, M. V. Abello et al., "Increase in TNF- $\alpha$ and inducible nitric oxide synthase-expressing dendritic cells in psoriasis and reduction with efalizumab (anti-CD1la)," Proceedings of the National Academy of Sciences of the United States of America, vol. 102, no. 52, pp. 19057-19062, 2005.

[24] M. B. M. Teunissen, C. W. Koomen, R. De Waal Malefyt, E. A. Wierenga, and J. D. Bos, "Interleukin-17 and interferon$\gamma$ synergize in the enhancement of proinflammatory cytokine production by human keratinocytes," Journal of Investigative Dermatology, vol. 111, no. 4, pp. 645-649, 1998.

[25] K. Nakajima, T. Kanda, M. Takaishi et al., "Distinct roles of IL23 and IL-17 in the development of psoriasis-like lesions in a mouse model," Journal of Immunology, vol. 186, no. 7, pp. 44814489, 2011.

[26] K. Nakajima, "Critical role of the interleukin-23//T-helper 17 cell axis in the pathogenesis of psoriasis," Journal of Dermatology, vol. 39, no. 3, pp. 219-224, 2012.

[27] J. T. Elder, A. T. Bruce, J. E. Gudjonsson et al., "Molecular dissection of psoriasis: integrating genetics and biology," Journal of Investigative Dermatology, vol. 130, no. 5, pp. 1213-1226, 2010.

[28] E. Toichi, G. Torres, T. S. McCormick et al., "An anti-IL-12p40 antibody down-regulates type 1 cytokines, chemokines, and IL12/IL-23 in psoriasis," Journal of Immunology, vol. 177, no. 7, pp. 4917-4926, 2006.

[29] M. T. Wiekowski, M. W. Leach, E. W. Evans et al., "Ubiquitous transgenic expression of the IL-23 subunit p19 induces multiorgan inflammation, runting, infertility, and premature death," Journal of Immunology, vol. 166, no. 12, pp. 7563-7570, 2001.

[30] J. R. Chan, W. Blumenschein, E. Murphy et al., "IL-23 stimulates epidermal hyperplasia via TNF and IL-20R2-dependent mechanisms with implications for psoriasis pathogenesis," Journal of Experimental Medicine, vol. 203, no. 12, pp. 2577-2587, 2006.

[31] K. Wolk, E. Witte, E. Wallace et al., "IL-22 regulates the expression of genes responsible for antimicrobial defense, cellular differentiation, and mobility in keratinocytes: a potential role in psoriasis," European Journal of Immunology, vol. 36, no. 5, pp. 1309-1323, 2006.

[32] K. Boniface, F. Bernard, M. Garcia, A. L. Gurney, J. Lecron, and F. Morel, "IL-22 inhibits epidermal differentiation and induces proinflammatory gene expression and migration of human keratinocytes," Journal of Immunology, vol. 174, no. 6, pp. 3695$3702,2005$.

[33] L. C. Zaba, I. Cardinale, P. Gilleaudeau et al., "Amelioration of epidermal hyperplasia by TNF inhibition is associated with reduced Th17 responses," The Journal of Experimental Medicine, vol. 204, no. 13, pp. 3183-3194, 2007.

[34] O. Arican, M. Aral, S. Sasmaz, and P. Ciragil, "Serum levels of TNF- $\alpha$, IFN- $\gamma$, IL-6, IL-8, IL-12, IL-17, and IL-18 in patients with active psoriasis and correlation with disease severity," Mediators of Inflammation, vol. 2005, no. 5, pp. 273-279, 2005.

[35] R. J. Xavier and D. K. Podolsky, "Unravelling the pathogenesis of inflammatory bowel disease," Nature, vol. 448, no. 7152, pp. 427-434, 2007.

[36] F. Powrie, M. W. Leach, S. Mauze, S. Menon, L. B. Caddle, and R. L. Coffman, "Inhibition of Th1 responses prevents inflammatory bowel disease in scid mice reconstituted with CD45RBhi CD $4^{+}$ T cells," Immunity, vol. 1, no. 7, pp. 553-562, 1994.

[37] S. Hue, P. Ahern, S. Buonocore et al., "Interleukin-23 drives innate and T cell-mediated intestinal inflammation," Journal of Experimental Medicine, vol. 203, no. 11, pp. 2473-2483, 2006.

[38] M. C. Kullberg, D. Jankovic, C. G. Feng et al., "IL-23 plays a key role in Helicobacter hepaticus-induced $\mathrm{T}$ cell-dependent colitis," Journal of Experimental Medicine, vol. 203, no. 11, pp. 2485-2494, 2006.

[39] R. H. Duerr, K. D. Taylor, S. R. Brant et al., "A genome-wide association study identifies IL23R as an inflammatory bowel disease gene," Science, vol. 314, no. 5804, pp. 1461-1463, 2006.

[40] L. A. Zenewicz, G. D. Yancopoulos, D. M. Valenzuela, A. J. Murphy, S. Stevens, and R. A. Flavell, "Innate and adaptive interleukin-22 protects mice from inflammatory bowel disease," Immunity, vol. 29, no. 6, pp. 947-957, 2008.

[41] A. Andoh, Z. Zhang, O. Inatomi et al., "Interleukin-22, a member of the IL-10 subfamily, induces inflammatory responses in colonic subepithelial myofibroblasts," Gastroenterology, vol. 129, no. 3, pp. 969-984, 2005.

[42] M. Veldhoen, K. Hirota, A. M. Westendorf et al., "The aryl hydrocarbon receptor links TH17-cell-mediated autoimmunity to environmental toxins," Nature, vol. 453, no. 7191, pp. 106-109, 2008.

[43] S. Trifari, C. D. Kaplan, E. H. Tran, N. K. Crellin, and H. Spits, "Identification of a human helper $\mathrm{T}$ cell population that has abundant production of interleukin 22 and is distinct from TH17, TH1 and TH2 cells," Nature Immunology, vol. 10, no. 8, pp. 864-871, 2009.

[44] I. Monteleone, A. Rizzo, M. Sarra et al., "Aryl hydrocarbon receptor-induced signals up-regulate IL-22 production and inhibit inflammation in the gastrointestinal tract," Gastroenterology, vol. 141, no. 1, pp. 237.e1-248.e1, 2011.

[45] X. O. Yang, S. H. Chang, H. Park et al., "Regulation of inflammatory responses by IL-17F," The Journal of Experimental Medicine, vol. 205, no. 5, pp. 1063-1075, 2008.

[46] A. Ogawa, A. Andoh, Y. Araki, T. Bamba, and Y. Fujiyama, "Neutralization of interleukin-17 aggravates dextran sulfate sodium-induced colitis in mice," Clinical Immunology, vol. 110, no. 1, pp. 55-62, 2004.

[47] D. Yen, J. Cheung, H. Scheerens et al., "IL-23 is essential for T cell-mediated colitis and promotes inflammation via IL-17 and IL-6," Journal of Clinical Investigation, vol. 116, no. 5, pp. 13101316, 2006.

[48] W. O’Connor Jr., M. Kamanaka, C. J. Booth et al., "A protective function for interleukin 17A in $\mathrm{T}$ cell-mediated intestinal inflammation," Nature Immunology, vol. 10, no. 6, pp. 603-609, 2009.

[49] M. J. McGeachy, Y. Chen, C. M. Tato et al., "The interleukin 23 receptor is essential for the terminal differentiation of interleukin 17-producing effector T helper cells in vivo," Nature Immunology, vol. 10, no. 3, pp. 314-324, 2009. 
[50] A. Awasthi, L. Riol-Blanco, A. Jäger et al., "Cutting Edge: IL-23 receptor GFP reporter mice reveal distinct populations of IL17-producing cells," Journal of Immunology, vol. 182, no. 10, pp. 5904-5908, 2009.

[51] Y. Komiyama, S. Nakae, T. Matsuki et al., "IL-17 plays an important role in the development of experimental autoimmune encephalomyelitis," Journal of Immunology, vol. 177, no. 1, pp. 566-573, 2006.

[52] H. H. Hofstetter, S. M. Ibrahim, D. Koczan et al., “Therapeutic efficacy of IL-17 neutralization in murine experimental autoimmune encephalomyelitis," Cellular Immunology, vol. 237, no. 2, pp. 123-130, 2005.

[53] K. Kreymborg, R. Etzensperger, L. Dumoutier et al., "IL-22 is expressed by Thl7 cells in an IL-23-dependent fashion, but not required for the development of autoimmune encephalomyelitis," Journal of Immunology, vol. 179, no. 12, pp. 8098-8104, 2007.

[54] D. Matusevicius, P. Kivisäkk, B. He et al., "Interleukin-17 mRNA expression in blood and CSF mononuclear cells is augmented in multiple sclerosis," Multiple Sclerosis, vol. 5, no. 2, pp. 101-104, 1999.

[55] C. Lock, G. Hermans, R. Pedotti et al., "Gene-microarray analysis of multiple sclerosis lesions yields new targets validated in autoimmune encephalomyelitis," Nature Medicine, vol. 8, no. 5, pp. 500-508, 2002.

[56] Y. Chen, C. L. Langrish, B. Mckenzie et al., "Anti-IL-23 therapy inhibits multiple inflammatory pathways and ameliorates autoimmune encephalomyelitis," Journal of Clinical Investigation, vol. 116, no. 5, pp. 1317-1326, 2006.

[57] M. I. Koenders and W. B. Van Den Berg, “Translational minireview series on Th17 cells: are Thelper 17 cells really pathogenic in autoimmunity?" Clinical and Experimental Immunology, vol. 159, no. 2, pp. 131-136, 2010.

[58] S. Hwang and H. Kim, "Expression of IL-17 homologs and their receptors in the synovial cells of rheumatoid arthritis patients," Molecules and Cells, vol. 19, no. 2, pp. 180-184, 2005.

[59] M. Chabaud, J. M. Durand, N. Buchs et al., "Human interleukin17: a T cell-derived proinflammatory cytokine produced by the rheumatoid synovium," Arthritis Rheum, vol. 42, no. 5, pp. $963-$ 970, 1999.

[60] M. Ziolkowska, A. Koc, G. Luszczykiewicz et al., "High levels of IL-17 in rheumatoid arthritis patients: IL-15 triggers in vitro IL17 production via cyclosporin A-sensitive mechanism," Journal of Immunology, vol. 164, no. 5, pp. 2832-2838, 2000.

[61] E. Lubberts, L. A. B. Joosten, F. A. J. Van de Loo, P. Schwarzenberger, J. Kolls, and W. B. Van den Berg, "Overexpression of IL-17 in the knee joint of collagen type II immunized mice promotes collagen arthritis and aggravates joint destruction," Inflammation Research, vol. 51, no. 2, pp. 102-104, 2002.

[62] H. Ikeuchi, T. Kuroiwa, N. Hiramatsu et al., "Expression of interleukin-22 in rheumatoid arthritis: potential role as a proinflammatory cytokine," Arthritis and Rheumatism, vol. 52, no. 4, pp. 1037-1046, 2005.

[63] H.-R. Kim, H.-S. Kim, M.-K. Park, M.-L. Cho, S.-H. Lee, and H.-Y. Kim, "The clinical role of IL-23p19 in patients with rheumatoid arthritis," Scandinavian Journal of Rheumatology, vol. 36, no. 4, pp. 259-264, 2007.

[64] H.-R. Kim, M.-L. Cho, K.-W. Kim et al., "Up-regulation of IL23p19 expression in rheumatoid arthritis synovial fibroblasts by IL-17 through PI3-kinase-, NF- $\kappa \mathrm{B}$ - and p38 MAPK-dependent signalling pathways," Rheumatology, vol. 46, no. 1, pp. 57-64, 2007.
[65] M. C. Honorati, R. Meliconi, L. Pulsatelli, S. Canè, L. Frizziero, and A. Facchini, "High in vivo expression of interleukin-17 receptor in synovial endothelial cells and chondrocytes from arthritis patients," Rheumatology, vol. 40, no. 5, pp. 522-527, 2001.

[66] E. Lubberts, M. I. Koenders, B. Oppers-Walgreen et al., "Treatment with a neutralizing anti-murine interleukin-17 antibody after the onset of collagen-induced arthritis reduces joint inflammation, cartilage destruction, and bone erosion," Arthritis and Rheumatism, vol. 50, no. 2, pp. 650-659, 2004.

[67] C. Zhang, J. Zhang, B. Yang, and C. Wu, "Cyclosporin A inhibits the production of IL-17 by memory Th17 cells from healthy individuals and patients with rheumatoid arthritis," Cytokine, vol. 42, no. 3, pp. 345-352, 2008.

[68] M. I. Koenders, J. K. Kolls, B. Oppers-Walgreen et al., "Interleukin-17 receptor deficiency results in impaired synovial expression of interleukin-1 and matrix metalloproteinases 3, 9, and 13 and prevents cartilage destruction during chronic reactivated streptococcal cell wall-induced arthritis," Arthritis and Rheumatism, vol. 52, no. 10, pp. 3239-3247, 2005.

[69] M. I. Koenders, E. Lubberts, F. A. J. Van De Loo et al., "Interleukin-17 acts independently of TNF- $\alpha$ under arthritic conditions," Journal of Immunology, vol. 176, no. 10, pp. 62626269, 2006.

[70] H. Paust, J. Turner, O. M. Steinmetz et al., "The IL-23/Th17 axis contributes to renal injury in experimental glomerulonephritis," Journal of the American Society of Nephrology, vol. 20, no. 5, pp. 969-979, 2009.

[71] J. Turner, H. Paust, O. M. Steinmetz, and U. Panzer, “The Th17 immune response in renal inflammation," Kidney international, vol. 77, no. 12, pp. 1070-1075, 2010.

[72] X. Dong, L. A. Bachman, M. N. Miller, K. A. Nath, and M. D. Griffin, "Dendritic cells facilitate accumulation of IL-17 T cells in the kidney following acute renal obstruction," Kidney International, vol. 74, no. 10, pp. 1294-1309, 2008.

[73] A. R. Kitching, A. L. Turner, T. Semple et al., "Experimental autoimmune anti-glomerular basement membrane glomerulonephritis: a protective role for IFN- $\gamma$," Journal of the American Society of Nephrology, vol. 15, no. 7, pp. 1764-1774, 2004.

[74] J. D. Ooi, R. K. S. Phoon, S. R. Holdsworth, and A. R. Kitching, "IL-23, not IL-12, directs autoimmunity to the goodpasture antigen," Journal of the American Society of Nephrology, vol. 20, no. 5, pp. 980-989, 2009.

[75] L. Li, L. Huang, A. L. Vergis et al., "IL-17 produced by neutrophils regulates IFN- $\gamma$-mediated neutrophil migration in mouse kidney ischemia-reperfusion injury," Journal of Clinical Investigation, vol. 120, no. 1, pp. 331-342, 2010.

[76] C. Van Kooten, J. G. Boonstra, M. E. Paape et al., "Interleukin17 activates human renal epithelial cells in vitro and is expressed during renal allograft rejection," Journal of the American Society of Nephrology, vol. 9, no. 8, pp. 1526-1534, 1998.

[77] B. C. Kwan, L. Tam, K. Lai et al., “The gene expression of type 17 T-helper cell-related cytokines in the urinary sediment of patients with systemic lupus erythematosus," Rheumatology, vol. 48, no. 12, pp. 1491-1497, 2009.

[78] J. Yang, Y. Chu, X. Yang et al., "Th17 and natural treg cell population dynamics in systemic lupus erythematosus," Arthritis and Rheumatism, vol. 60, no. 5, pp. 1472-1483, 2009.

[79] X. F. Zhao, H. F. Pan, H. Yuan et al., "Increased serum interleukin 17 in patients with systemic lupus erythematosus," Mol Biol Rep, vol. 37, no. 1, pp. 81-85, 2010. 
[80] X. Y. Yang, H. Y. Wang, X. Y. Zhao, L. J. Wang, Q. H. Lv, and Q. Q. Wang, "Th22, but not Th17 might be a good index to predict the tissue involvement of systemic lupus erythematosus," Journal of Clinical Immunology, vol. 33, no. 4, pp. 767-774.

[81] T. Duhen, R. Geiger, D. Jarrossay, A. Lanzavecchia, and F. Sallusto, "Production of interleukin 22 but not interleukin 17 by a subset of human skin-homing memory T cells," Nature Immunology, vol. 10, no. 8, pp. 857-863, 2009.

[82] G. Tiegs, J. Hentschel, and A. Wendel, "A T cell-dependent experimental liver injury in mice inducible by concanavalin A," Journal of Clinical Investigation, vol. 90, no. 1, pp. 196-203, 1992.

[83] S. Radaeva, R. Sun, H. Pan, F. Hong, and B. Gao, "Interleukin 22 (IL-22) plays a protective role in T cell-mediated murine hepatitis: IL-22 is a survival factor for hepatocytes via STAT3 activation," Hepatology, vol. 39, no. 5, pp. 1332-1342, 2004.

[84] L. A. Zenewicz, G. D. Yancopoulos, D. M. Valenzuela, A. J. Murphy, M. Karow, and R. A. Flavell, "Interleukin-22 but not interleukin-17 provides protection to hepatocytes during acute liver inflammation," Immunity, vol. 27, no. 4, pp. 647-659, 2007.

[85] T. Nagata, L. McKinley, J. J. Peschon, J. F. Alcorn, S. J. Aujla, and J. K. Kolls, "Requirement of IL-17RA in con a induced hepatitis and negative regulation of IL-17 production in mouse T cells," Journal of Immunology, vol. 181, no. 11, pp. 7473-7479, 2008.

[86] M. Xu, N. Morishima, I. Mizoguchi et al., "Regulation of the development of acute hepatitis by IL-23 through IL-22 and IL17 production," European Journal of Immunology, vol. 41, no. 10, pp. 2828-2839, 2011.

[87] S. Yan, L. Wang, N. Liu, Y. Wang, and Y. Chu, "Critical role of interleukin-17/interleukin-17 receptor axis in mediating Con Ainduced hepatitis," Immunology and Cell Biology, vol. 90, no. 4, pp. 421-428, 2012.

[88] E. Smith, M. A. Stark, A. Zarbock et al., "IL-17A inhibits the expansion of IL-17A-producing T cells in mice through "shortloop" inhibition via IL-17 receptor," Journal of Immunology, vol. 181, no. 2, pp. 1357-1364, 2008.

[89] I. N. Crispe, "IL-17 in liver injury: an inflammatory issue?" Immunology \& Cell Biology, vol. 90, no. 4, pp. 369-370, 2012.

[90] F. Lafdil, H. Wang, O. Park et al., "Myeloid STAT3 inhibits T cell-mediated hepatitis by regulating $\mathrm{T}$ helper 1 cytokine and interleukin-17 production," Gastroenterology, vol. 137, no. 6, pp. 2125.e2-2135.e2, 2009.

[91] F. Radtke and K. Raj, "The role of Notch in tumorigenesis: oncogene or tumour suppressor," Nature Reviews Cancer, vol. 3, no. 10 , pp. $756-767,2003$.

[92] B. A. Osborne and L. M. Minter, "Notch signalling during peripheral T-cell activation and differentiation," Nature Reviews Immunology, vol. 7, no. 1, pp. 64-75, 2007.

[93] M. S. Alam, Y. Maekawa, A. Kitamura et al., "Notch signaling drives IL-22 secretion in $\mathrm{CD}^{+}{ }^{+} \mathrm{T}$ cells by stimulating the aryl hydrocarbon receptor," Proceedings of the National Academy of Sciences of the United States of America, vol. 107, no. 13, pp. 59435948, 2010.

[94] Y. Tagawa, P. Matthys, H. Heremans et al., "Bimodal role of endogenous interleukin-6 in concanavalin A-induced hepatitis in mice," Journal of Leukocyte Biology, vol. 67, no. 1, pp. 90-96, 2000.

[95] S. Aggarwal, N. Ghilardi, M. Xie, F. J. De Sauvage, and A. L. Gurney, "Interleukin-23 promotes a distinct CD4 T cell activation state characterized by the production of interleukin17," Journal of Biological Chemistry, vol. 278, no. 3, pp. 1910-1914, 2003.
[96] S. Eyerich, K. Eyerich, D. Pennino et al., “Th22 cells represent a distinct human $\mathrm{T}$ cell subset involved in epidermal immunity and remodeling," Journal of Clinical Investigation, vol. 119, no. 12, pp. 3573-3585, 2009.

[97] Y. Zhang, M. A. Cobleigh, J. Lian et al., "A proinflammatory role for interleukin-22 in the immune response to hepatitis B virus," Gastroenterology, vol. 141, no. 5, pp. 1897-1906, 2011.

[98] R. Jiang, Z. Tan, L. Deng et al., "Interleukin-22 promotes human hepatocellular carcinoma by activation of STAT3," Hepatology, vol. 54, no. 3, pp. 900-909, 2011.

[99] J. Zhang, Z. Zhang, F. Lin et al., "Interleukin-17-producing $\mathrm{CD} 4^{+} \mathrm{T}$ cells increase with severity of liver damage in patients with chronic hepatitis B," Hepatology, vol. 51, no. 1, pp. 81-91, 2010.

[100] D. C. Gritz and I. G. Wong, "Incidence and prevalence of uveitis in Northern California: the Northern California Epidemiology of Uveitis Study," Ophthalmology, vol. 111, no. 3, pp. 491-500, 2004.

[101] T. Yoshimura, K. Sonoda, Y. Miyazaki et al., "Differential roles for IFN- $\gamma$ and IL-17 in experimental autoimmune uveoretinitis," International Immunology, vol. 20, no. 2, pp. 209-214, 2008.

[102] R. B. Nussenblatt, "Bench to bedside: new approaches to the immunotherapy of uveitic disease," International Reviews of Immunology, vol. 21, no. 2-3, pp. 273-289, 2002.

[103] D. Luger and R. R. Caspi, "New perspectives on effector mechanisms in uveitis," Seminars in Immunopathology, vol. 30, no. 2, pp. 135-143, 2008.

[104] R. R. Caspi, "A look at autoimmunity and inflammation in the eye," Journal of Clinical Investigation, vol. 120, no. 9, pp. 30733083, 2010.

[105] A. Amadi-Obi, C. Yu, X. Liu et al., "TH17 cells contribute to uveitis and scleritis and are expanded by IL- 2 and inhibited by IL-27/STAT1," Nature Medicine, vol. 13, no. 6, pp. 711-718, 2007.

[106] D. Luger, P. B. Silver, J. Tang et al., "Either a Th17 or a Th1 effector response can drive autoimmunity: conditions of disease induction affect dominant effector category," Journal of Experimental Medicine, vol. 205, no. 4, pp. 799-810, 2008.

[107] Y. Peng, G. Han, H. Shao, Y. Wang, H. J. Kaplan, and D. Sun, "Characterization of IL-17" interphotoreceptor retinoidbinding protein-specific $\mathrm{T}$ cells in experimental autoimmune uveitis," Investigative Ophthalmology and Visual Science, vol. 48, no. 9, pp. 4153-4161, 2007.

[108] Y. Ke, K. Liu, G. Huang et al., "Anti-inflammatory role of IL-17 in experimental autoimmune uveitis," Journal of Immunology, vol. 182, no. 5, pp. 3183-3190, 2009.

[109] Y. Ke, D. Sun, G. Jiang, H. J. Kaplan, and H. Shao, "IL22-induced regulatory $\mathrm{CD} 1 \mathrm{~b}^{+}$APCs suppress experimental autoimmune uveitis," Journal of Immunology, vol. 187, no. 5, pp. 2130-2139, 2011.

[110] R. R. Caspi, T. Kuwabara, and R. B. Nussenblatt, "Characterization of a suppressor cell line which downgrades experimental autoimmune uveoretinitis in the rat," Journal of Immunology, vol. 140, no. 8, pp. 2579-2584, 1988.

[111] Y. Peng, H. Shao, Y. Ke et al., "Minimally activated CD8 autoreactive T cells specific for IRBP express a high level of Foxp3 and are functionally suppressive," Investigative Ophthalmology and Visual Science, vol. 48, no. 5, pp. 2178-2184, 2007.

[112] M. K. Jenkins, "The ups and downs of T cell costimulation," Immunity, vol. 1, no. 6, pp. 443-446, 1994.

[113] C. A. Janeway Jr. and K. Bottomly, "Signals and signs for lymphocyte responses," Cell, vol. 76, no. 2, pp. 275-285, 1994. 
[114] L. M. Bagenstose, R. K. Agarwal, P. B. Silver et al., "Disruption of CD40/CD40-ligand interactions in a retinal autoimmunity model results in protection without tolerance," Journal of Immunology, vol. 175, no. 1, pp. 124-130, 2005.

[115] T. Fukai, A. A. Okada, J. Sakai et al., "The role of costimulatory molecules B7-1 and B7-2 in mice with experimental antoimmune uveoretinitis," Graefe's Archive for Clinical and Experimental Ophthalmology, vol. 237, no. 11, pp. 928-933, 1999.

[116] K. Namba, K. Ogasawara, N. Kitaichi et al., "Amelioration of experimental autoimmune uveoretinitis by pretreatment with a pathogenic peptide in liposome and anti-CD40 ligand monoclonal antibody," Journal of Immunology, vol. 165, no. 6, pp. 2962-2969, 2000.

[117] J. Maertzdorf, A. D. M. E. Osterhaus, and G. M. G. M. Verjans, "IL-17 expression in human herpetic stromal keratitis: modulatory effects on chemokine production by corneal fibroblasts," Journal of Immunology, vol. 169, no. 10, pp. 5897-5903, 2002.

[118] C. S. De Paiva, S. Chotikavanich, S. B. Pangelinan et al., "IL-17 disrupts corneal barrier following desiccating stress," Mucosal Immunology, vol. 2, no. 3, pp. 243-253, 2009.

[119] X. Zheng, F. Bian, P. Ma et al., "Induction of Th17 differentiation by corneal epithelial-derived cytokines," Journal of Cellular Physiology, vol. 222, no. 1, pp. 95-102, 2010.

[120] A. Suryawanshi, T. Veiga-Parga, N. K. Rajasagi et al., "Role of il-17 and th17 cells in herpes simplex virus-induced corneal immunopathology," Journal of Immunology, vol. 187, no. 4, pp. 1919-1930, 2011.

[121] T. Veiga-Parga, A. Suryawanshi, and B. T. Rouse, "Controlling viral immuno-inflammatory lesions by modulating aryl hydrocarbon receptor signaling," PLoS Pathogens, vol. 7, no. 12, Article ID e1002427, 2011.

[122] S. M. J. Fleiszig, T. S. Zaidi, E. L. Fletcher, M. J. Preston, and G. B. Pier, "Pseudomonas aeruginosa invades corneal epithelial cells during experimental infection," Infection and Immunity, vol. 62, no. 8, pp. 3485-3493, 1994.

[123] S. Hohki, N. Ohguro, H. Haruta et al., "Blockade of interleukin6 signaling suppresses experimental autoimmune uveoretinitis by the inhibition of inflammatory Th17 responses," Experimental Eye Research, vol. 91, no. 2, pp. 162-170, 2010.

[124] I. Arranz-Valsero, U. Schulze, L. Contreras-Ruiz et al., "Involvement of corneal epithelial cells in the Th17 response in an in vitro bacterial inflammation model," Molecular Vision, vol. 19, pp. 85-99, 2013.

[125] C. F. Barker and R. E. Billingham, "Immunologically privileged sites," Advances in Immunology, vol. 25, no. C, pp. 1-54, 1978.

[126] M. Itoh, H. Terayama, M. Naito, Y. Ogawa, and S. Tainosho, "Tissue microcircumstances for leukocytic infiltration into the testis and epididymis in mice," Journal of Reproductive Immunology, vol. 67, no. 1-2, pp. 57-67, 2005.

[127] M. Fijak and A. Meinhardt, "The testis in immune privilege," Immunological Reviews, vol. 213, no. 1, pp. 66-81, 2006.

[128] M. P. Hedger and D. B. Hales, "Immunophysiology of the male reproductive tract," in Knobil's and Neill's Physiology of Reproduction, J. D. Neill, Ed., pp. 1195-1286, Elsevier, Amsterdam, The Netherlands, 2006.

[129] A. B. Tompkins, P. Hutchinson, D. M. De Kretser, and M. P. Hedger, "Characterization of lymphocytes in the adult rat testis by flow cytometry: effects of activin and transforming growth factor $\beta$ on lymphocyte subsets in vitro," Biology of Reproduction, vol. 58, no. 4, pp. 943-951, 1998.
[130] A. Mukasa, K. Hiromatsu, G. Matsuzaki, R. O’Brien, W. Born, and K. Nomoto, "Bacterial infection of the testis leading to autoaggressive immunity triggers apparently opposed responses of $\alpha \beta$ and $\gamma \delta$ T cells," Journal of Immunology, vol. 155, no. 4, pp. 2047-2056, 1995.

[131] M. P. Hedger, “Testicular leukocytes: what are they doing?" Reviews of Reproduction, vol. 2, no. 1, pp. 38-47, 1997.

[132] H. Schuppe and A. Meinhardt, "Immune privilege and inflammation of the testis," Chemical immunology and allergy, vol. 88, pp. 1-14, 2005.

[133] W. Weidner, W. Krause, and M. Ludwig, "Relevance of male accessory gland infection for subsequent fertility with special focus on prostatitis," Human Reproduction Update, vol. 5, no. 5, pp. 421-432, 1999.

[134] G. Haidl, J. P. Allam, and H.-C. Schuppe, "Chronic epididymitis: impact on semen parameters and therapeutic options," Andrologia, vol. 40, no. 2, pp. 92-96, 2008.

[135] H.-C. Schuppe, A. Meinhardt, J. P. Allam, M. Bergmann, W. Weidner, and G. Haidl, "Chronic orchitis: a neglected cause of male infertility?” Andrologia, vol. 40, no. 2, pp. 84-91, 2008.

[136] P. Jacobo, V. A. Guazzone, S. Jarazo-Dietrich, M. S. Theas, and L. Lustig, "Differential changes in $\mathrm{CD}^{+}$and $\mathrm{CD} 8^{+}$effector and regulatory $\mathrm{T}$ lymphocyte subsets in the testis of rats undergoing autoimmune orchitis," Journal of Reproductive Immunology, vol. 81, no. 1, pp. 44-54, 2009.

[137] Y.-G. Duan, C.-F. Yu, N. Novak et al., "Immunodeviation towards a Th17 immune response associated with testicular damage in azoospermic men," International Journal of Andrology, vol. 34, no. 6, pp. e536-e545, 2011.

[138] H. Terayama, M. Naito, N. Qu et al., "Intratesticular expression of mRNAs of both interferon $\gamma$ and tumor necrosis factor $\alpha$ is significantly increased in experimental autoimmune orchitis in mice," Journal of Reproduction and Development, vol. 57, no. 2, pp. 296-302, 2011.

[139] J. P. Stephan, V. Syed, and B. Jegou, "Regulation of sertoli cell IL-1 and IL-6 production in vitro," Molecular and Cellular Endocrinology, vol. 134, no. 2, pp. 109-118, 1997.

[140] S. Nakae, Y. Komiyama, A. Nambu et al., "Antigen-specific T cell sensitization is impaired in Il-17-deficient mice, causing suppression of allergic cellular and humoral responses," Immunity, vol. 17, no. 3, pp. 375-387, 2002.

[141] M. S. Sundrud, S. B. Koralov, M. Feuerer et al., "Halofuginone inhibits th17 cell differentiation by activating the amino acid starvation response," Science, vol. 324, no. 5932, pp. 1334-1338, 2009.

[142] S. Schnyder-Candrian, D. Togbe, I. Couillin et al., "Interleukin17 is a negative regulator of established allergic asthma," Journal of Experimental Medicine, vol. 203, no. 12, pp. 2715-2725, 2006.

[143] C. Song, L. Luo, Z. Lei et al., "IL-17-producing alveolar macrophages mediate allergic lung inflammation related to asthma," Journal of Immunology, vol. 181, no. 9, pp. 6117-6124, 2008.

[144] B. Schnyder, C. Lima, and S. Schnyder-Candrian, "Interleukin22 is a negative regulator of the allergic response," Cytokine, vol. 50, no. 2, pp. 220-227, 2010.

[145] J. Peng, X. O. Yang, S. H. Chang, J. Yang, and C. Dong, "IL23 signaling enhances Th2 polarization and regulates allergic airway inflammation," Cell Research, vol. 20, no. 1, pp. 62-71, 2010.

[146] H. Wakashin, K. Hirose, Y. Maezawa et al., "IL-23 and Th17 cells enhance Th2-cell-mediated eosinophilic airway inflammation 
in mice," American Journal of Respiratory and Critical Care Medicine, vol. 178, no. 10, pp. 1023-1032, 2008.

[147] S. J. Aujla and J. F. Alcorn, "TH17 cells in asthma and inflammation," Biochimica et Biophysica Acta, vol. 1810, no. 11, pp. 10661079, 2011.

[148] S. Lajoie, I. P. Lewkowich, Y. Suzuki et al., "Complementmediated regulation of the IL-17A axis is a central genetic determinant of the severity of experimental allergic asthma," Nature Immunology, vol. 11, no. 10, pp. 928-935, 2010.

[149] J. Y. Wang, S. D. Shyur, W. H. Wang et al., "The polymorphisms of interleukin 17A (IL17A) gene and its association with pediatric asthma in Taiwanese population," Allergy: European Journal of Allergy and Clinical Immunology, vol. 64, no. 7, pp. 1056-1060, 2009. 


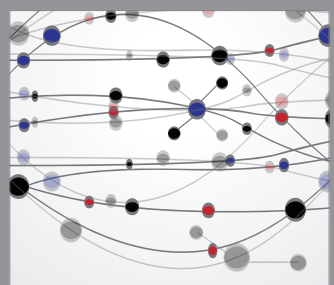

The Scientific World Journal
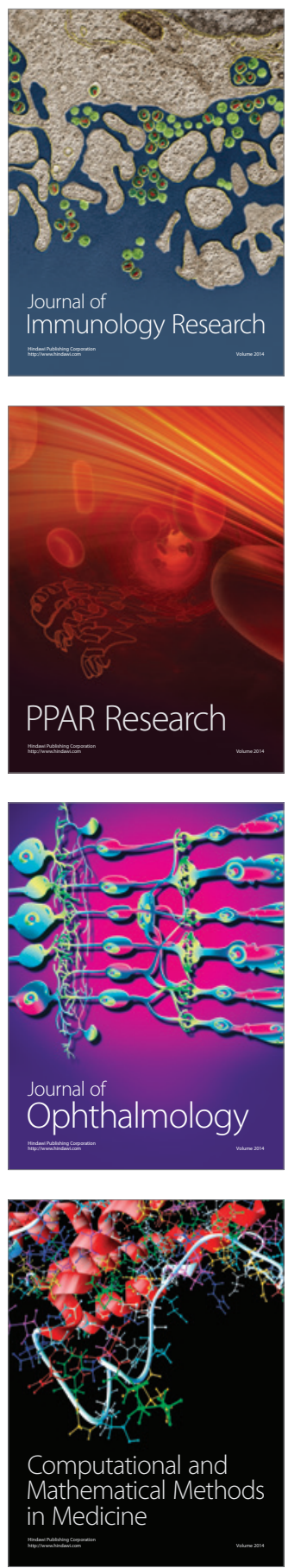

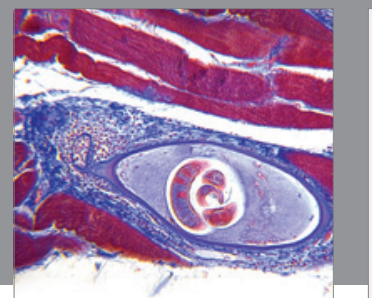

Gastroenterology

Research and Practice
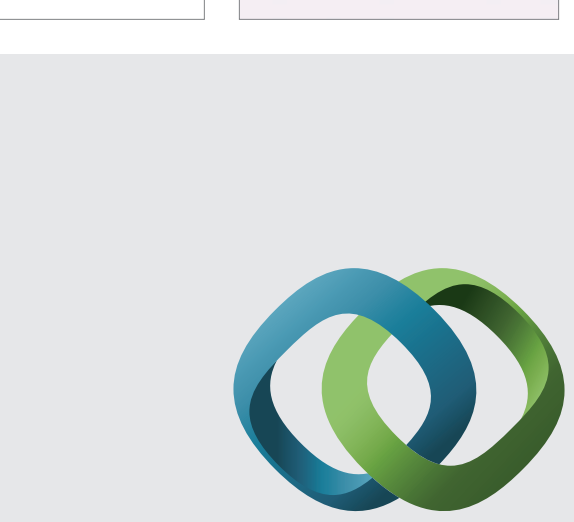

\section{Hindawi}

Submit your manuscripts at

http://www.hindawi.com
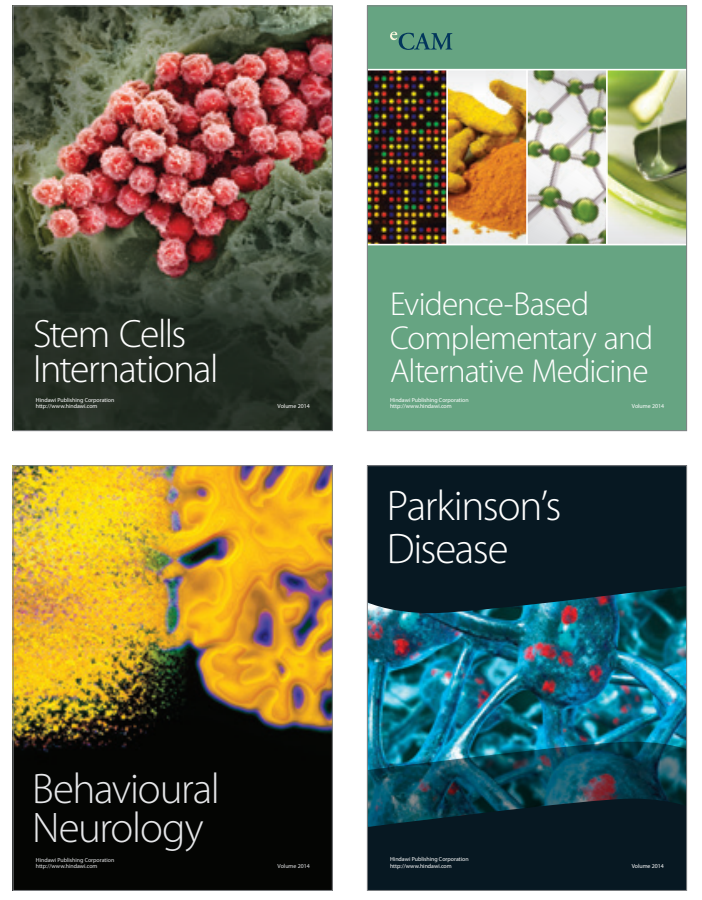
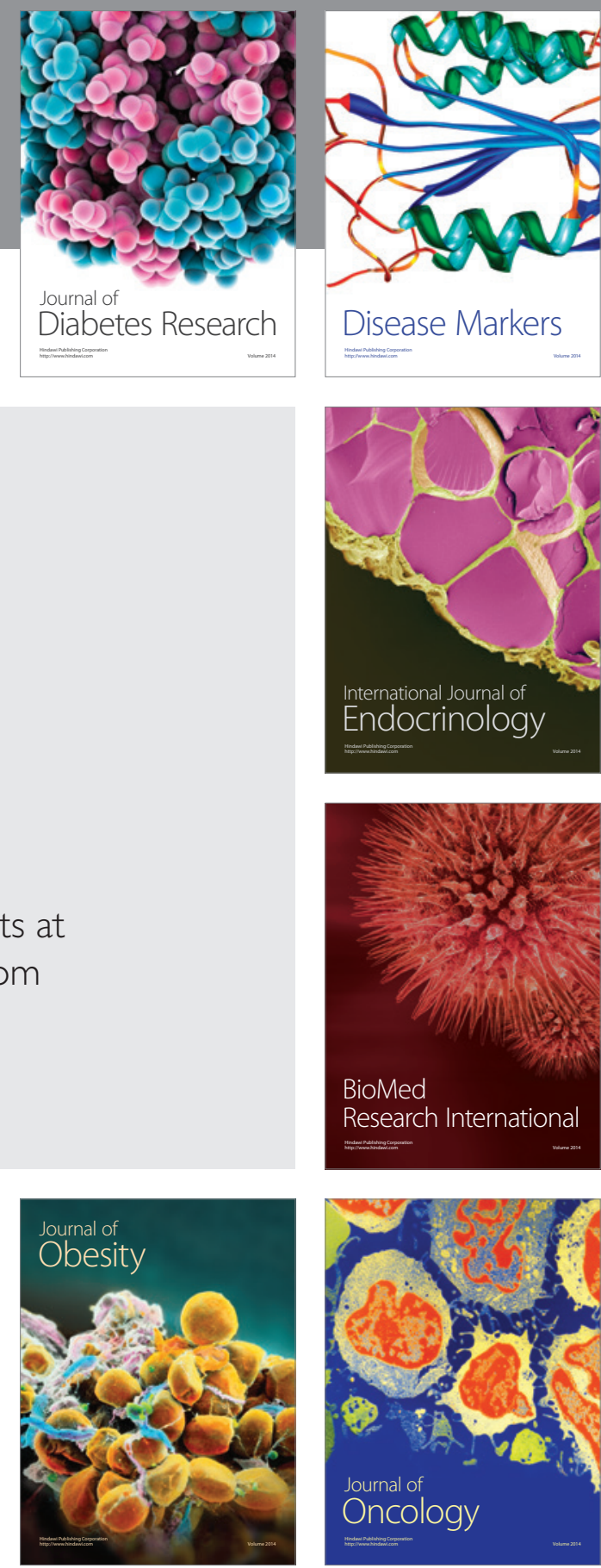

Disease Markers
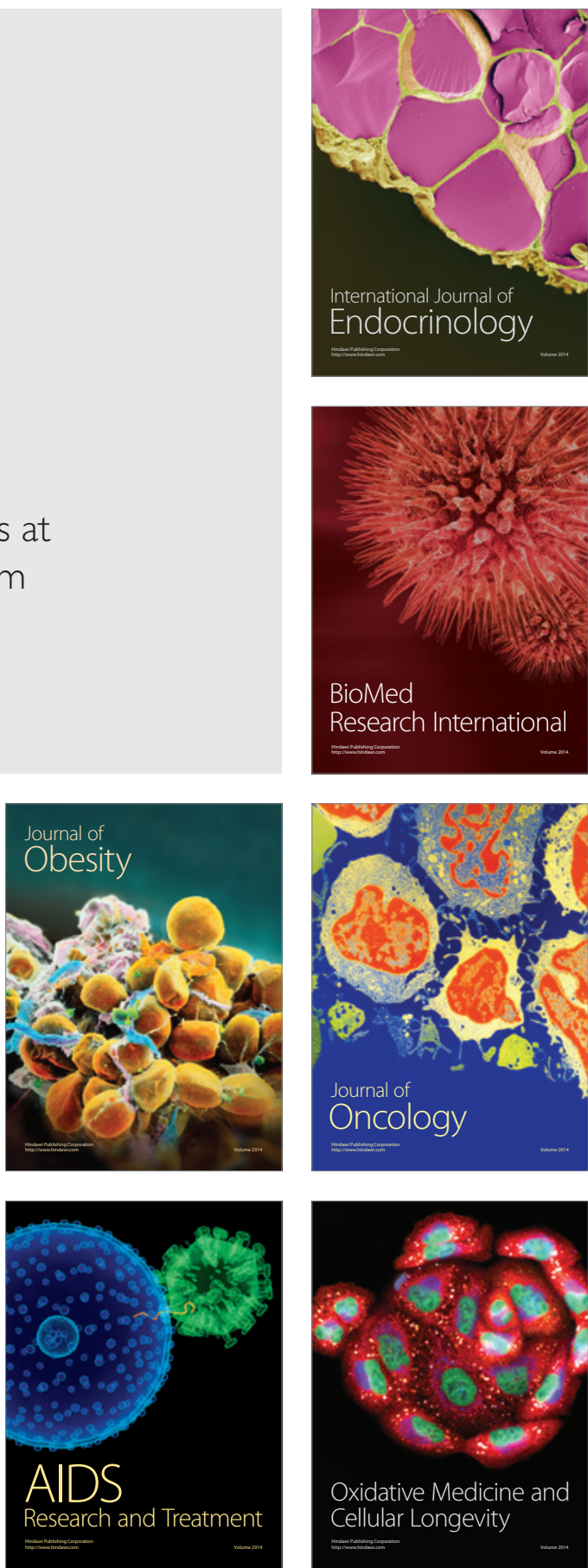